\title{
The generation and evaluation of recombinant human IgA specific for Plasmodium falciparum merozoite surface protein 1-19 (PfMSP1 $\left.{ }_{19}\right)$
}

Jianguo Shi ${ }^{1}$, Richard S McIntosh', Jaime Adame-Gallegos ${ }^{1}$, Prabhjyot K Dehal ${ }^{2}$, Marjolein van Egmond ${ }^{3}$, Jan van de Winkel ${ }^{4}$, Simon J Draper ${ }^{5}$, Emily K Forbes ${ }^{5}$, Patrick H Corran ${ }^{6}$, Anthony A Holder ${ }^{7}$, Jenny M Woof ${ }^{2}$ and Richard J Pleass ${ }^{1 *}$

\begin{abstract}
Background: Human immunoglobulin $\mathrm{G}(\mathrm{lgG})$ plays an important role in mediating protective immune responses to malaria. Although human serum immunoglobulin A $(\lg A)$ is the second most abundant class of antibody in the circulation, its contribution, if any, to protective responses against malaria is not clear.

Results: To explore the mechanism(s) by which IgA may mediate a protective effect, we generated fully human IgA specific for the C-terminal 19-kDa region of Plasmodium falciparum merozoite surface protein 1 (PfMSP $\left.1_{19}\right)$, a major target of protective immune responses. This novel human IgA bound antigen with an affinity comparable to that seen for an epitope-matched protective human IgG1. Furthermore, the human IgA induced significantly higher NADPH-mediated oxidative bursts and degranulation from human neutrophils than the epitope-matched human IgG1 from which it was derived. Despite showing efficacy in in vitro functional assays, the human IgA failed to protect against parasite challenge in vivo in mice transgenic for the human Fca receptor (FcaRl/CD89). A minority of the animals treated with IgA, irrespective of FcaRI expression, showed elevated serum TNF- $\alpha$ levels and concomitant mouse anti-human antibody (MAHA) responses.

Conclusions: The lack of protection afforded by MSP1 ${ }_{19}$-specific IgA against parasite challenge in mice transgenic for human FcaRl suggests that this antibody class does not play a major role in control of infection. However, we cannot exclude the possibility that protective capacity may have been compromised in this model due to rapid clearance and inappropriate bio-distribution of $\lg \mathrm{A}$, and differences in FcaRl expression profile between humans and transgenic mice.
\end{abstract}

\section{Background}

There is increasing interest in exploring the therapeutic potential of alternative antibody (Ab) classes to IgG, which to date has been the most popular choice, with over 160 examples currently in clinical trials for the treatment of diverse cancers, infectious diseases and auto-immune conditions [1,2]. We recently developed a novel humanized mouse model to show that human IgG1 specific for Plasmodium falciparum merozoite surface protein 1-19 (Pf $\left.\mathrm{MSP}_{19}\right)$ could protect animals from malaria in passive transfer experiments [3].

\footnotetext{
* Correspondence: richard.pleass@liv.ac.uk

'Institute of Genetics, Queen's Medical Centre, University of Nottingham, NG7 2UH, UK

Full list of author information is available at the end of the article
}

However there are numerous drawbacks to using IgGbased therapies in malaria, including competition for FcR binding, from high levels of parasite-induced nonspecific IgG [4], that warrant the exploration of other serum $\mathrm{Ab}$ classes for use against infections of blood.

FcaRI (CD89) targeting with IgA could offer potential for controlling malaria with therapeutic antibodies [5]. Unlike IgM, IgG and IgE, which are implicated in immune evasion [6], placental malaria [7] and severe malaria respectively [8], IgA has not been implicated in malaria pathology, arguing for its consideration in $\mathrm{Ab}$ therapy. Although a direct role for murine IgA in killing of rodent malaria parasites has not been investigated in vivo because mice lack an equivalent of human FcaRI, Plasmodium-specific IgA has been detected at high
C Biomed Central

(c) 2011 Shi et al; licensee BioMed Central Ltd. This is an Open Access article distributed under the terms of the Creative Commons Attribution License (http://creativecommons.org/licenses/by/2.0), which permits unrestricted use, distribution, and reproduction in any medium, provided the original work is properly cited. 
levels in serum $[9,10]$, and breast milk $[10,11]$, in humans from endemic areas.

Ligation of the myeloid FcaRI induces cytokine release and can stimulate a respiratory burst $[12,13]$, and FcoRI is better than Fc $\gamma$ Rs at triggering lysis of Ab-targeted tumors as well as phagocytosis of pathogens coated with Abs, both in humans and mice $[13,14]$. Human FcaRI is expressed on the majority of white blood cells, including neutrophils, monocytes, macrophages, eosinophils, platelets and NK cells, suggesting it to be an ideal target for systemic IgA-mediated therapy $[4,5,13,15,16]$. The finding that Fc $\alpha$ RI is a discrete modulator of the immune system mediating both anti- and pro-inflammatory functions indicates that further exploration of the role of human IgA in malaria is necessary [17]. We recently described a mandatory role for human $\mathrm{Fc} \alpha \mathrm{RI}$ in mediating protection from tuberculosis using recombinant human IgA [18].

To address the role of human IgA in malaria, we generated a recombinant IgA recognizing the $P f \mathrm{MSP}_{19}$ epitope, matched to a human IgG1 shown previously to transfer passive protection in the Fc $\gamma$ RI (CD64) transgenic mouse model [3]. This recombinant IgA was then tested in passive transfer experiments for efficacy in controlling malaria in vivo in human FcaRI (CD89) transgenic mice.

\section{Results}

\section{Characterization of $P f M S P 1_{19}$-specific human IgA}

PfMSP1 $1_{19}$-specific human IgA isolated from HEK-293T transfectant culture supernatants by affinity-chromatography appeared pure (Figure 1). It ran ahead of recombinant anti-NIP polymeric IgA2 and IgM under native conditions (Figure 1A), suggesting that it is mainly monomeric, a conclusion supported by size-exclusion chromatographic analysis (data not shown). The antiNIP antibodies are in polymeric form having been produced in J-chain expressing transfectants. On reducing SDS-PAGE gels, the recombinant IgA resolved into heavy and light chain bands of the anticipated molecular mass (Figure 1B). The heavy chain was recognized by an isotype-specific Ab. The recombinant human IgA recognized a $P$. falciparum $\mathrm{MSP}_{19}$-GST fusion protein in ELISAs and by indirect IFA produced a characteristic pattern of MSP1 reactivity in schizonts, merozoites, and ring-stage parasites from $P$. falciparum and Plasmodium berghei parasites transgenic for $P f \mathrm{MSP}_{19}$ (data not shown). Importantly, surface plasmon resonance (SPR) analysis revealed no reduction in affinity for $P f \mathrm{MSP} 1_{19}$ when compared with the parental IgG1 antibody (Table 1). The binding constants remain essentially the same, and although the affinity for $P f M S P 1_{19}$ is less than that of a well characterized mouse monoclonal antibody (mAb) 12.10 specific for $P f M S P 1_{19}$ (Table 1), it is still appreciable.
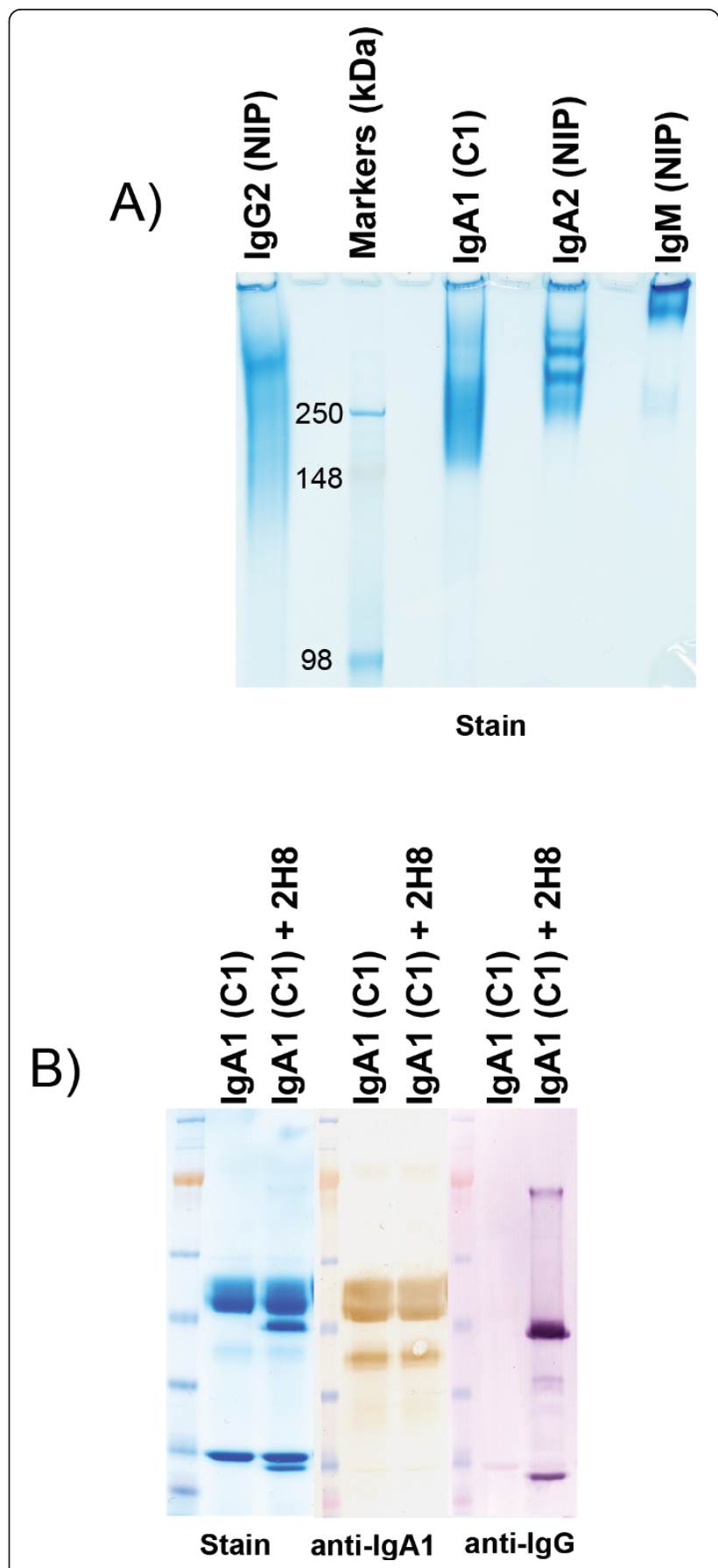

Figure 1 Characterization of purified recombinant $P F M S P 1_{19}$ specific human IgA. $5 \mu \mathrm{g}$ purified recombinant Abs were run under (A) non-denaturing (native) conditions on 6\% acrylamide Tris-glycine gels (Novex) or under (B) denaturing reducing conditions on NuPAGE 4-12\% Bis-Tris gradient SDS gels (Novex). In the former, anti-NIP IgA2 (AbD Serotec, Kidlington, UK) and anti-NIP IgM (AbD Serotec) were included as polymeric controls. In the latter, gels were either stained with Coomassie or transferred to nitrocellulose and probed with antihuman IgA or anti-mouse IgG-Fc reagents, and lanes containing both $\operatorname{lgA}$ and the anti-FcaRI mAb $2 \mathrm{H} 8$ were included. The IgA is recognized by anti-human IgA-specific reagents but not by anti-mouse lgG-Fc reactive Abs that only recognize $\mathrm{mAb} 2 \mathrm{H} 8$. 
Table 1 Analysis of the binding properties of $P f M S P 1_{19^{-}}$ specific human IgA (C1), human IgG1 (C1) and mouse mAb 12.10 to immobilized GST-PfMSP $1_{19}$ by SPR.

\begin{tabular}{llll}
\hline & $\mathbf{K}_{\text {ass }}$ & $\mathbf{K}_{\text {diss }}$ & $\mathbf{K}_{\mathbf{d}}$ \\
\hline & $\left(\mathrm{M}^{-1} \mathrm{sec}^{-1}\right)$ & $\left(\mathrm{sec}^{-1}\right)$ & $(\mathrm{M})$ \\
$\mathrm{mAb} 12.10$ & $5.37 \times 10^{5}$ & $5.5 \times 10^{-6}$ & $1 \times 10^{-11}$ \\
$\operatorname{lgG1}(\mathrm{C} 1)$ & $4.4 \times 10^{3}$ & $1.0 \times 10^{-4}$ & $2.3 \times 10^{-8}$ \\
$\operatorname{lgA}(\mathrm{C} 1)$ & $6.5 \times 10^{3}$ & $1.7 \times 10^{-4}$ & $2.6 \times 10^{-8}$ \\
\hline
\end{tabular}

$\left(\mathrm{K}_{\mathrm{d}}=\mathrm{K}_{\text {diss }} / \mathrm{K}_{\text {ass }}\right)$

Methodology described in refs $[3,13]$.

2. IgA1 triggers $P f M S P 1_{19}$-specific neutrophil nicotinamide adenine dinucleotide phosphate (NADPH) oxidase activation through $\mathrm{Fc} \alpha \mathrm{RI}$ cross-linking

We next assessed the ability of this novel IgA to interact with human FcaRI and induce NADPH oxidase activation (respiratory burst) and degranulation in human blood neutrophils (Figure 2). For neutrophils, luminol chemiluminescence provides a read out of NADPH oxidase activation and myeloperoxidase release [12,13]. When attached to $P f M S P 1_{19}$-GST-coated plates, the human IgA induced significantly greater respiratory bursts than if the IgA was coated directly to the bottom of the plate in the absence of antigen (Figure 2), suggesting that binding to antigen allows the IgA to be presented to neutrophil Fc $\alpha$ RI in an optimal configuration for receptor cross-linking and triggering of functional responses. We have observed that this IgA induces greater respiratory bursts from human neutrophils than the epitope-matched human IgG1 from which this Ab was derived [3]. This ability of human IgA to

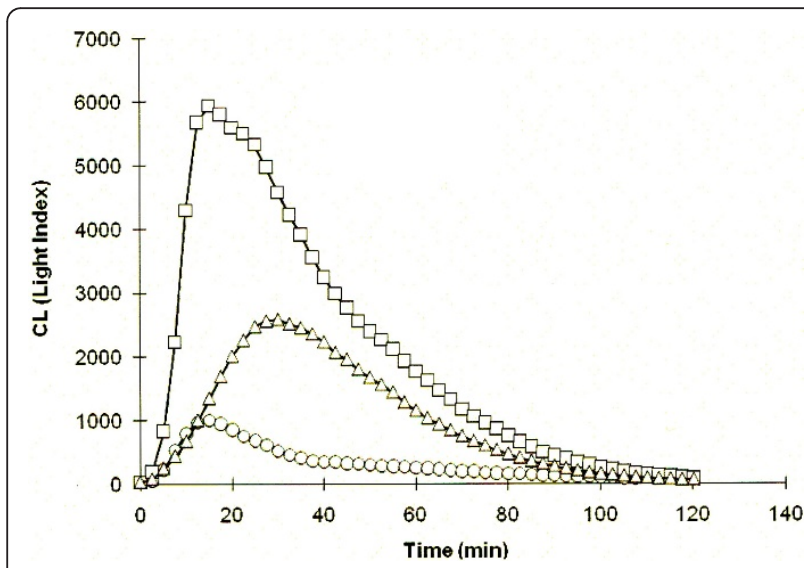

Figure 2 Recombinant human $P f M S P 1_{19}$-specific IgA is functional. Stimulation of neutrophil NADPH oxidative bursts using $50 \mu \mathrm{g}$ of IgA attached to GST-PFMSP1 ${ }_{19}$-coated microtiter plates (open squares), or $50 \mu \mathrm{g}$ of $\operatorname{lgA}$ attached directly to the bottom of the plate (open triangles) or no Ab (open curcles). Data are presented as mean chemiluminescence (CL; arbitary units) from triplicate wells using neutrophils from a single human donor as previously described $[3,12,13]$. outperform human IgG1 at inducing free oxygen radicals and activation of human neutrophils has also been observed for human IgA recognizing the homologous antigen from Plasmodium yoelii [13].

\section{Passive transfer of human IgA into wild type or human Fc $\alpha$ RI (CD89) transgenic mice has no effect on the course of a malaria infection}

Because FcoRI is absent in mice due to a translocation event in the leukocyte receptor complex, we tested the ability of the human IgA to protect from malaria using human FcoRI transgenic mice $[19,20]$. These mice have been used to show protection from mucosally administered pathogens but have not been directly investigated in relation to blood parasites or in the context of human IgA administered systemically [21,22]. Blood granulocytes and a proportion of monocytes from these transgenic mice constitutively express functional human Fc $\alpha$ RI and bind human IgA (Additional file 1, Figure S1). In vivo experiments with $P$. berghei transgenic for $P f \mathrm{MSP}_{19}$ highlighted that three intraperitoneal (i.p.) inoculations of IgA (total dose of $1.5 \mathrm{mg} \mathrm{Ab}$ per mouse) was unable to suppress a lethal blood stage challenge infection in these animals in contrast to previous observations with the epitope-matched human IgG1 passively administered into human Fc $\gamma$ RI (CD64) transgenic animals [3] (Figure 3).

\section{Passive transfer of $P f M S P 1_{19}$-specific human IgA1 into mice induces TNF- $\alpha$ and mouse anti-human antibody (MAHA) responses in some animals}

We observed that animals passively immunised with PfMSP1 19 -specific human IgA by the i.p. route showed greater adverse clinical signs according to the Laboratory Animal Science Association (LASA) indices, including severe piloerection \& lethargy, after challenge with malaria parasites than control groups of animals. To investigate the underlying basis for these observed detrimental effects of the passively transferred human IgA we analyzed serum cytokines responses in all the animals using the cytometric bead array mouse Th1/Th2 10plex kit (Bender Medsystems) on day 10 post-challenge when all mice were killed. We observed significantly elevated levels of TNF- $\alpha$ in animals treated with human IgA compared with control animals given PBS, irrespective of genetic background (Figure 4), although extreme levels of TNF- $\alpha$ were only seen in four of the fourteen mice tested. The difference in TNF- $\alpha$ levels between the transgenic and non-transgenic groups administered IgA was not statistically significant (Figure 4). No significant differences over baseline levels of IL-4, IL-10, IFN- $\gamma$, IL-6, IL-17, GM-CSF were observed between the groups, although IL- 2 and IL- $1 \alpha$ were raised in animals given IgA when compared with PBS 


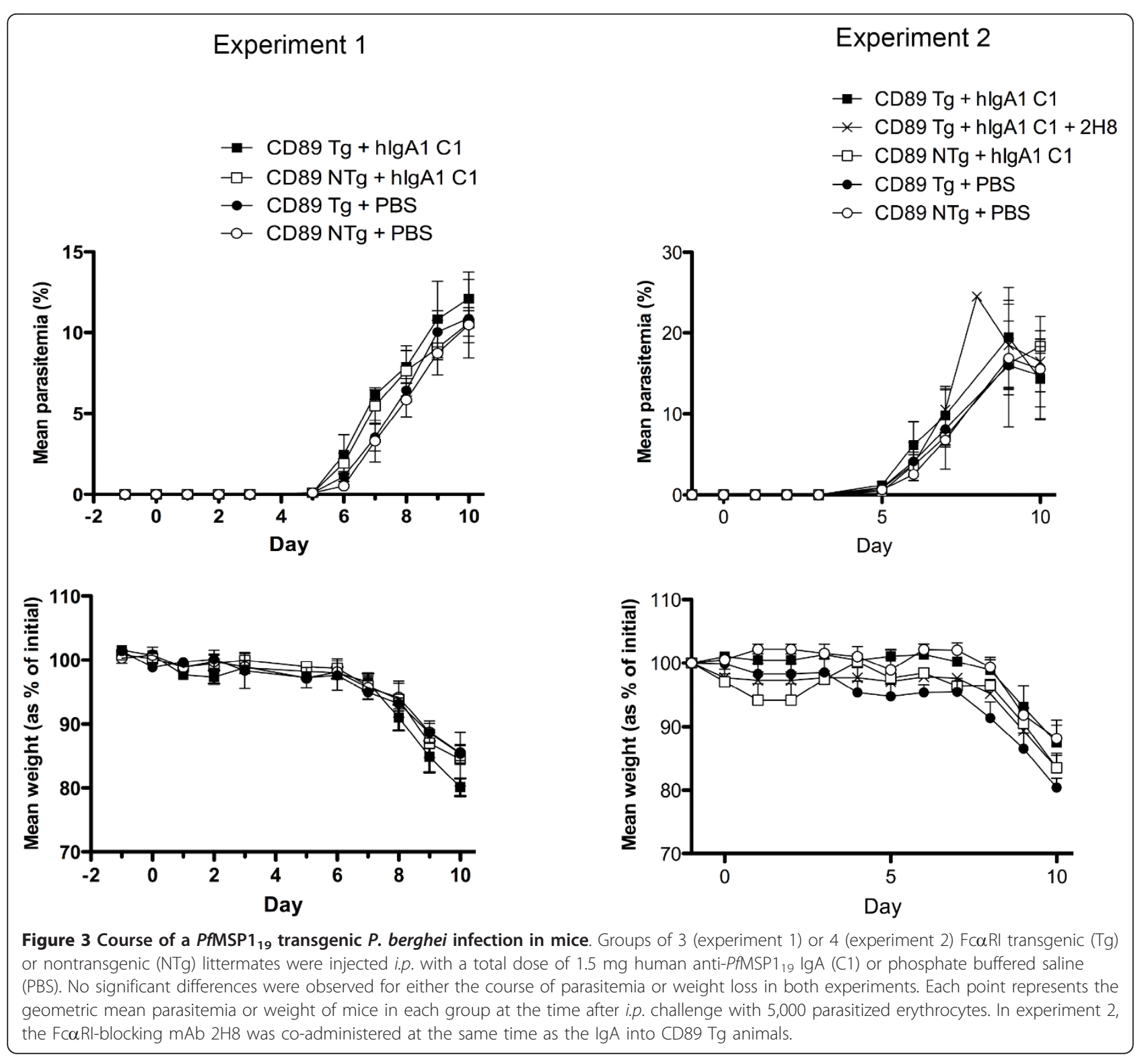

(data not shown). Co-administration of $\mathrm{mAb} 2 \mathrm{H} 8$, a mouse mAb that binds to human Fc $\alpha$ RI blocking the human IgA binding site [23], at the time of IgA delivery, failed to dramatically alter the course of parasitemia (Figure 3) or the development of TNF- $\alpha$ responses (not shown). The induction of elevated TNF- $\alpha$ was therefore not dependent on the presence of the human FcoRI transgene, but more likely due to some uncharacterized effect of the $P f M S P 11_{19}$-specific IgA, a result supported by the raised TNF- $\alpha$ levels observed in non-transgenic animals also given the antibody. These high levels of TNF- $\alpha$ were present despite the absence of detectable PfMSP $1_{19}$-specific IgA in the final bleeds (in contrast to similar experiments with IgG1), confirming that the half-life of the passively transferred human IgA in mice is less than that for human IgG1. All animals given PfMSP $1_{19}$-specific IgA (irrespective of genetic background), also made significant mouse anti-human IgA responses on day 10 as assessed by ELISA (Additional file 1, Figure S2), suggesting that the high levels of inflammatory cytokines observed may be a consequence of mounting an anti-human IgA immune response and are not the result of malaria infection per se, as these cytokines were not observed in challenged mice given PBS.

\section{Discussion}

We describe the development of a fully human IgA with specificity for a very well characterized epitope on $\mathrm{MSP}_{19}$ from $P$. falciparum, useful for dissecting human 


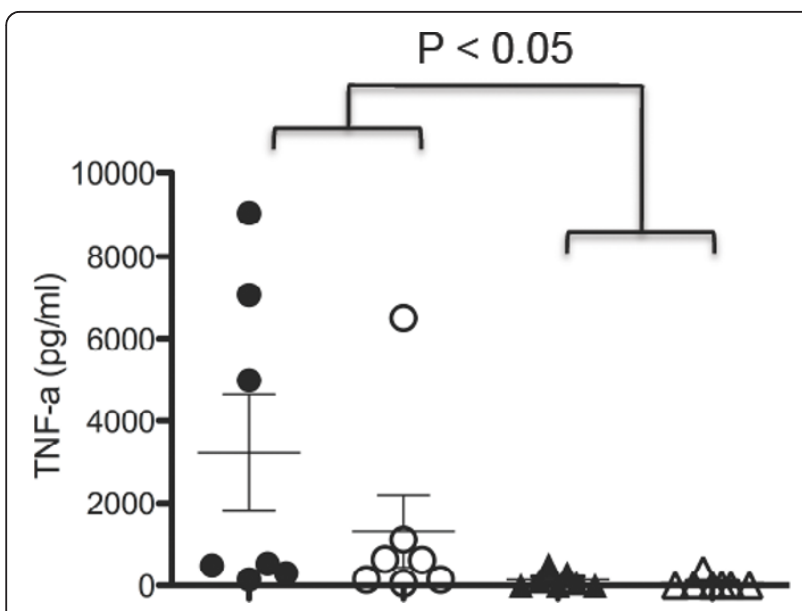

Figure 4 Plasma TNF- $\alpha$ responses in animals given i.p. PfMSP1 $_{19}$-specific IgA. Each bar represents the mean concentration of TNF- $\alpha \pm$ SE from each group of mice in Fig. 3. Levels of TNF- $\alpha$ are shown for CD89 Tg (Tg) animals passively transferred with human IgA (closed circles) or PBS (open circles) against non-transgenic (NTg) littermates also given IgA (closed triangles) or PBS (open triangles). Each plasma sample was assayed in triplicate determinations for each animal. Differences between the groups were analyzed using Dunn's multiple comparison test and statistically significant differences are indicated.

Fc receptor mechanisms involved in immunity to human malaria [3].

This novel IgA was generated from a human IgG1 mAb (C1), previously shown to protect human Fc $\gamma \mathrm{RI}$ (CD64) transgenic mice (but not wild type animals) from a lethal challenge with rodent malaria $(P$. berghei) transgenic for the P. falciparum MSP $1_{19}\left(P f \mathrm{MSP}_{19}\right)$ antigen [3]. The engineered IgA recognized parasites in infected erythrocytes and bound $P f M S P 1_{19}$ with comparable kinetics to that observed with the parental IgG1 from which it was derived. Despite triggering potent and functional in vitro responses the IgA failed to protect human Fc $\alpha$ RI transgenic mice from a malaria infection. Although the injected IgA is mostly monomeric, and therefore binds transiently to Fc $\alpha \mathrm{R}$, immune-complexes formed on engaging $\mathrm{PfMSP}_{19}$ on merozoites would be expected to bind avidly to FcoRI $[1,2]$. We also tried without success to passively protect the CD89 transgenic animals with sera from rabbits immunized with PfMSP $1_{19}$ or plasma from vaccinated humans or humans from endemic regions with significant levels of anti-Pf MSP $1_{19}$ human IgA antibodies by ELISA (data not shown). This is noteworthy, as clinical protection from $P$. falciparum malaria, has recently been shown to correlate with neutrophil respiratory bursts induced by merozoites opsonized with human serum antibodies [24]. This important study demonstrated that immune African sera depleted of IgG by protein-G Sepharose chromatography (but presumably still containing IgA), gave negligible activity in their antibody-dependent respiratory burst assays (ADRB). Whilst highlighting an absolute requirement for IgG, this finding is however difficult to reconcile with the observed ability here of $P f M S P 1_{19}$-specific human IgA to induce very effective luminol NADPH-oxidase mediated respiratory bursts and degranulation from human blood neutrophils (Figure 2) $[12,13]$.

One explanation for the failure of the IgA to protect against malarial challenge may be that it is difficult for IgA administered i.p. to leave the peritoneum and reach the circulation and other parts of the body, where any protective effects would presumably be mediated. Transfer of IgG from peritoneum to other body compartments may be assisted, at least in part, through interaction with FcRn, an IgG receptor present on a variety of cell types, capable of bidirectional transport across epithelial surfaces and involved in control of IgG turnover [25]. IgA, in contrast, is unable to bind FcRn, and may be more reliant on diffusion to reach the circulation and distribute within other body compartments. This may also explain why recombinant IgA when administered intra-nasally was particularly effective at controlling tuberculosis [18].

Another explanation for the lack of in vivo efficacy may be that the administered IgA was cleared very rapidly from the mouse, before it had sufficient opportunity to mediate any protective effects. Unlike humans, where the half-life of the chiefly monomeric serum IgA is approximately 4-5 days [26], in mice monomeric IgA has a half-life of just 24 hours [27]. IgG is cleared much more slowly due to interaction with FcRn, and therefore when administered i.p. presumably has a much greater opportunity for functional impact.

A third possibility is that the Fc $\alpha$ RI in the transgenic mice is not expressed on the cell types critical for protection at sufficiently high levels, or on a sufficient proportion of these cells, or on cells located within the required body compartment. For example, in contrast to the situation in humans, only a subpopulation of the monocytes of the transgenic mice express human FcaRI, and peritoneal macrophages and platelets exhibit no expression [19].

These three possibilities, taken together, suggest that the Fc $\alpha$ RI transgenic mouse, although undoubtedly the best model currently available, may not afford the means to fully assess the capability of human IgA to offer protection in the human setting.

This is the first recombinant human IgA to target $P f \mathrm{MSP}_{19}$. However, in exploring the role of IgA in malaria, others have tested recombinant human IgA1 and IgA2 localized on the surface of polystyrene beads in a two-step antibody-dependent cellular inhibition (ADCI) assay [28]. In contrast to human IgG1 and IgG3, 
neither IgA1 or IgA2 were found to stimulate in vitro ADCI of malaria parasites by human monocytes [28]. Human monocytes express Fc $\alpha$ RI and induce parasite inhibitory TNF- $\alpha$ [29], and may therefore have been expected to engage in ADCI. This finding is in keeping with the lack of an in vivo effect seen here, the data suggesting neutrophils rather than monocytes may fulfill this role, and with either human IgA targeting the $P$. berghei PfMSP $1_{19}$ transgenic, or earlier against $P$. yoelii $\mathrm{MSP}_{19}$ [13]. However, it will be necessary to generate epitope-matched murine IgAs (and IgGs) to determine if mouse monocytes/neutrophils are capable of ADCI/ ADRB and whether mouse IgA can protect against rodent malarias in vivo. Although no counterpart for human FcaRI is known in mice, mouse macrophages do bind mouse IgA, and Mac-2/galectin-3 (gal-3) has been suggested to be the receptor involved [30]. Interestingly, gal-3 is known to bind IgE, and there may be some mileage in developing recombinant IgE to investigate malaria infection, as mouse IgE can also bind Fc $\gamma$ RIV (which also binds IgG2a and IgG2b) on mouse monocytes [31]. Intriguingly, murine IgE has been shown to confer protection from P. berghei in C57BL/6 mice, and elevated anti-malarial IgE in asymptomatic individuals has been shown to associate with a reduced risk of subsequent clinical malaria in humans [32].

We observed that a small proportion of mice given the recombinant human IgA preparation in the context of a malaria infection developed significant mouse anti-human antibody responses (MAHA) with elevated TNF- $\alpha$ within 10 days of the last IgA dose, which were not observed in control animals challenged with malaria (Figure 4). Our observations suggest that the responses are not dependent on the presence of the Fc $\alpha$ RI transgene and therefore may represent a reaction to the administered IgA itself. Further experiments will be necessary to clarify whether the response noted is peculiar to the particular IgA preparation used which may contain undetected levels of aggregates, or the specificity of the IgA for the co-administered malarial parasite that might result in particular cross-linking events, or is a general effect associated with human IgA administration to mice in the absence of malaria challenge infection.

\section{Conclusions}

In summary, a novel $P f \mathrm{MSP} 1_{19}$-specific IgA did not show protective capability against parasite challenge in mice transgenic for human FcaRI. While this finding may indicate that IgA does not play a major role in protection against malaria, we cannot rule out the possibility that the findings reflect certain shortcomings of the mouse model used. Thus important differences in IgA half-life, IgA bio-distribution, and FcaRI expression profile between the transgenic mice and humans may have compromised the antibody's ability to mediate protective effects, and further experimentation will be required to fully dissect the role of IgA in human malaria.

\section{Methods}

\section{Ethics Statement}

Informed written consent was obtained from all participants and approval for the use of human samples was obtained from the Ethical Committees at Nottingham and Oxford. All animal experiments were approved by the Home Office and performed in accordance with UK guidelines and regulations (PPL 40/2753).

\section{Construction of human IgA}

The variable heavy $(\mathrm{VH})$ gene from $\mathrm{pVH}-\mathrm{C} 1-\gamma 1$ was subcloned as a BssHII/BstEII fragment upstream of the human IgA1 $\alpha$-chain constant region sequence previously inserted into the mammalian expression vector pcDNA3.1/Hygro (Invitrogen, UK), to create pVH-C1a1. Mammalian HEK293T cells (European Collection of Cell Cultures) were co-transfected with linearized pVH-C1- $\alpha 1$ and pVK-C1-Express (expression vector containing the corresponding $\mathrm{C} 1$ variable light (VL) chain upstream of the human $\mathrm{C} \kappa$ gene). Positive clones secreting $P f \mathrm{MSP} 1_{19}$-specific IgA were detected by enzyme-linked immunosorbent assay (ELISA) with recombinant $P f \mathrm{MSP}_{19}$ coated plates and by immunoblotting with goat anti-human IgA Abs conjugated to horseradish peroxidase (HRP) or alkaline phosphatase (AP) as previously described [3,13]. Recombinant $P f \mathrm{MSP}_{19}$ used in all ELISAs was generated as previously described [33]. From large-scale cultures, human IgA was purified by affinity chromatography on anti-human IgA agarose columns by FPLC (Sigma). The integrity and purity of the antibodies was verified by gel electrophoresis on both non-denaturing and denaturing gels according to the manufacturer's instructions (Novex) (see Figure 1).

\section{Luminol chemiluminescence assay of respiratory burst and myeloperoxidase release}

Neutrophils were isolated from heparinized blood taken from healthy volunteers by sedimentation of erythrocytes in 6\% (w/v) dextran T70 (GE Healthcare, U. $\mathrm{K}$.) in $0.9 \%(\mathrm{w} / \mathrm{v})$ saline at $37^{\circ} \mathrm{C}$ for $30 \mathrm{~min}$, followed by leukocyte separation on a discontinuous density gradient of Lymphoprep ( $\rho=1.077 \mathrm{~g} / \mathrm{cm}^{3}$; Nycomed, Birmingham, UK) over Ficoll-Hypaque ( $\rho=1.119 \mathrm{~g} /$ $\mathrm{cm}^{3}$ ), centrifuged at $700 \times g$ for $20 \mathrm{~min}$ at room temperature. Approval for the collection and use of human cells was obtained from the local Queen's Medical Centre ethical committee. Wells of 
chemiluminescence microtiter plates (Dynatech Laboratories, Billinghurst, Sussex, UK) were coated with $150 \mu \mathrm{l}$ of $P f \mathrm{MSP}_{19}$ at $5 \mu \mathrm{g} \mathrm{ml}{ }^{-1}$ or $50 \mu \mathrm{g}$ of IgA in coating buffer (0.1 M carbonate buffer, $\mathrm{pH}$ 9.6) and incubated overnight at $4^{\circ} \mathrm{C}$. After washing three times with PBS, $150 \mu \mathrm{l}$ of anti-PfMSP1 ${ }_{19} \operatorname{IgA}$ at $50 \mu \mathrm{g} \mathrm{ml}^{-1}$ was added to antigen coated wells. In each case, triplicate wells were prepared and left for $2 \mathrm{~h}$ at room temperature. After washing as before, $100 \mu \mathrm{l}$ of luminol [67 $\mu \mathrm{g} \mathrm{ml}^{-1}$ in Hank's buffered saline solution (HBSS) containing $20 \mathrm{mM}$ HEPES and $0.1 \mathrm{~g} / 100 \mathrm{ml}$ globulinfree BSA (HBSS/BSA)] were added to each well. After the addition of $50 \mu \mathrm{l}$ of purified neutrophils $\left(10^{6} / \mathrm{ml}\right.$ in HBSS/BSA) to each well, plates were transferred to a Microlumat LB96P luminometer, and the chemiluminescence measured at $2 \mathrm{~min}$ intervals for $120 \mathrm{~min}$ at $37^{\circ} \mathrm{C}$. Data were analyzed using Excel software.

\section{Cytokines}

Concentrations of GM-CSF, IFN- $\gamma$, IL-1 $\alpha$, IL-2, IL-4, IL-5, IL-6, IL-10, IL-17 and TNF- $\alpha$ in individual mouse sera were determined by flow cytometry using the FlowCytomix mouse Th1/Th2 10plex (BMS820FF) bead kit against known standard curves and according to manufacturer's instructions (Bender MedSystems). Beads were analyzed using a Beckman Coulter EPICS ALTRA flow cytometer (High Wycombe, Bucks, UK) and data analyzed with Bender MedSystems software.

\section{Passive immunization and parasite challenge}

Because of the lack of an animal model for P. falciparum and because mice do not express a homologue of human Fc $\alpha$ RI, human Fc $\alpha$ RI transgenic mice have been developed that express FcaRI on blood neutrophils and a proportion of their monocytes [Additional file 1, Figure 1 [22]]. Transgenic (Tg) Balb/c $\times$ Balb/c F1 mice 9-12 wks old and bred under specific pathogen-free conditions were used. Non-transgenic (NTg) littermates served as controls. Mice were screened for Fc $\alpha$ RI expression by PCR of whole blood using forward (5'-TGGGGCTTCGCACAGGGTCTTTA-3') and reverse (5'-CCAGCACACCGCAGTCGCCATAC-3') primers for human CD89, and by analysis of lysed whole blood on a FAC-Scan with PE-conjugated antihuman FcoRI (Additional file 1). Pf MSP1 $1_{19}$-specific IgA (at $0.5 \mathrm{mg} /$ injection) with or without $50 \mu \mathrm{g} /$ injection blocking mAb $2 \mathrm{H} 8$ (mouse IgG1 anti-human FcaRI) [23] was administered intraperitoneally (i.p.) on days $-1,0$ and day +1 with respect to parasite challenge. Parasitized erythrocytes (5000/mouse) derived from passaged mice infected with $P$. berghei parasites transgenic for P. falciparum MSP $1_{19}$ were injected i.p. at least $3 \mathrm{~h}$ after antibody treatment on day 0 as previously described $[3,13]$. Parasitemia was assessed daily on Giemsa reagent-stained blood smears.

\section{Additional material}

Additional file 1: Characterization of CD89 transgenic mice. FACS analysis of gated whole blood from CD89 negative or positive animals as assessed by PCR [19]. Gated neutrophils (R3, blue) and blood monocytes (R2, green) from positive animals used in this study bind PE-conjugated anti-human CD89 while those of CD89-negative animals do not. Anti-

human IgA responses are provoked in mice passively administered with recombinant human $\lg A$.

\section{Acknowledgements}

We thank Dr Cees van Kooten (University of Leiden, The Netherlands) for provision of $\mathrm{mAb} 2 \mathrm{H} 8$ and Professor Eleanor Riley for providing human plasma. We would also like to thank Tania de Koning-Ward \& Brendan Crabb (WEHI, Melbourne) for provision of the $P$. berghei transgenic parasites. The authors have declared no competing interests.

\section{Author details}

${ }^{1}$ Institute of Genetics, Queen's Medical Centre, University of Nottingham, NG7 2UH, UK. ²Division of Medical Sciences, University of Dundee Medical School, Ninewells Hospital, Dundee, DD1 9SY, UK. ${ }^{3}$ Department of Molecular Cell Biology and Immunology, VU Medical Centre, Amsterdam, 3508 TC, The Netherlands. ${ }^{4}$ Immunotherapy laboratory, Department of Immunology, University Medical Centre Utrecht, Utrecht, 3508 TC, The Netherlands. ${ }^{5}$ The Jenner Institute, University of Oxford, Oxford, OX3 7DQ, UK. ${ }^{6}$ Department of Infectious and Tropical Diseases, London School of Hygiene and Tropical Medicine, London, WC1E 7HT, UK. '7Division of Parasitology, National Institute for Medical Research, London, NW7 1AA, UK.

\section{Authors' contributions}

All authors read and approved the final manuscript. RM, JS, JA-G performed all animal experiments, Biacore analysis, generation of Abs, and ELISAs. RM and JS contributed equally to the manuscript. SJD, EKF, AH and PHC provided parasite, human and/or rabbit serum samples and critiqued the manuscript. PKD constructed the pcDNA3.1/Hygro based human IgA1 expression vector. MvE \& JvdW provided transgenic animals and important discussion. JMW provided laboratory facilities for vector production and wrote parts of the paper. RP conceived and designed the overall study, provided laboratory facilities, and wrote the paper.

\section{Competing interests}

The authors declare that they have no competing interests.

Received: 5 April 2011 Accepted: 22 July 2011 Published: 22 July 2011

\section{References}

1. Dechant $M$, Valerius T: IgA antibodies for cancer therapy. Crit Rev Oncol Hematol 2001, 39:69-77.

2. Corthésy B: Recombinant secretory immunoglobulin $A$ in passive immunotherapy: linking immunology and biotechnology. Curr Pharm Biotechnol 2003, 4:51-67.

3. Mclntosh RS, Shi J, Jennings RM, Chappel JC, de Koning-Ward TF, Smith T, Green J, van Egmond M, Leusen JH, Lazarou M, van de Winkel J, Jones TS, Crabb BS, Holder AA, Pleass RJ: The importance of human FcgammaRI in mediating protection to malaria. PLOS Pathog 2007, 3:e72.

4. Pleass RJ, Holder AA: Opinion: antibody-based therapies for malaria. Nat Rev Microbiol 2005, 3:893-899.

5. Shi J, Mclntosh RS, Pleass RJ: Antibody- and Fc-receptor-based therapeutics for malaria. Clin Sci (Lond) 2006, 110:11-19.

6. Barfod L, Dalgaard MB, Pleman ST, Ofori MF, Pleass RJ, Hviid L: Evasion of immunity to Plasmodium falciparum malaria by lgM masking of protective epitopes in infected erythrocyte surface-exposed PfEMP1. Proc Natl Acad Sci USA 2011. 
7. Flick K, Scholander C, Chen Q, Fernandez V, Pouvelle B, Gysin J, Wahlgren M: Role of nonimmune lgG bound to PfEMP1 in placental malaria. Science 2001, 293:2098-2100.

8. Perlmann P, Perlmann H, Flyg BW, Hagstedt M, Elghazali G, Worku S, Fernandez V, Rutta AS, Troye-Blomberg M: Immunoglobulin E, a pathogenic factor in Plasmodium falciparum malaria. Infect Immun 1997, 65:116-121.

9. Biswas S, Saxena QB, Roy A, Kabilan L: Naturally-Occurring PlasmodiumSpecific IgA Antibody in Humans from a Malaria Endemic Area. Journal of Biosciences 1995, 20:453-460.

10. Kassim OO, Ako-Anai KA, Torimiro SE, Hollowell GP, Okoye VC, Martin SK: Inhibitory factors in breastmilk, maternal and infant sera against in vitro growth of Plasmodium falciparum malaria parasite. J Trop Pediatr 2000, 46:92-96.

11. Leke RG, Ndansi R, Southerland NJ, Quakyi IA, Taylor DW: Identification of anti-Plasmodium falciparum antibodies in human breast milk. Scand J Immunol Suppl 1992, 11:17-22.

12. Pleass $R J$, Lang $M L$, Kerr MA, Woof JM: IgA is a more potent inducer of NADPH oxidase activation and degranulation in blood eosinophils than IgE. Mol Immunol 2007, 44:1401-1408.

13. Pleass RJ, Ogun SA, McGuinness DH, van de Winkel JG, Holder AA, Woof JM: Novel antimalarial antibodies highlight the importance of the antibody Fc region in mediating protection. Blood 2003, 102:4424-4430.

14. Otten MA, Rudolph E, Dechant M, Tuk CW, Reijmers RM, Beelen RH, van de Winkel JG, van Egmond M: Immature neutrophils mediate tumor cell killing via IgA but not IgG Fc receptors. J Immunol 2005, 174:5472-5480.

15. Qian K, Xie F, Gibson AW, Edberg JC, Kimberly RP, Wu J: Functional expression of IgA receptor FcalphaRI on human platelets. J Leukoc Biol 2008, 84:1492-1500.

16. Mota G, Manciulea M, Cosma E, Popescu I, Hirt M, Jensen-Jarolim E, Calugaru A, Galatiuc C, Regalia T, Tamandl D, Spittler A, Boltz-Nitulescu G: Human NK cells express Fc receptors for IgA which mediate signal transduction and target cell killing. Eur J Immunol 2003, 33:2197-2205.

17. Pasquier B, Launay $P$, Kanamaru Y, Moura IC, Pfirsch S, Ruffié C, Hénin D, Benhamou M, Pretolani M, Blank U, Monteiro RC: Identification of FcalphaRI as an inhibitory receptor that controls inflammation: dual role of FcRgamma ITAM. Immunity 2005, 22:31-42.

18. Balu S, Reljic R, Lewis MJ, Pleass RJ, Mclntosh R, van Kooten C, van Egmond $\mathrm{M}$, Challacombe S, Woof JM, Ivanyi J: A novel human IgA Monoclonal antibody protects against tuberculosis. J Immuno/ 2011, 186:3113-3119.

19. van Egmond $M$, van Vuuren $A J$, Morton $H C$, van Spriel $A B$, Shen $L$, Hofhuis FM, Saito T, Mayadas TN, Verbeek JS, van de Winkel JG: Human immunoglobulin A receptor (FcalphaRI, CD89) function in transgenic mice requires both FcR gamma chain and CR3 (CD11b/CD18). Blood 1999, 93:4387-4394.

20. van Egmond $M$, van Garderen $E$, van Spriel $A B$, Damen $C A$, van Amersfoort ES, van Zandbergen G, van Hattum J, Kuiper J, van de Winkel JG: FcalphaRI-positive liver Kupffer cells: reappraisal of the function of immunoglobulin A in immunity. Nat Med 2000, 6:680-685.

21. Hellwig SM, van Spriel AB, Schellekens JF, Mooi FR, van de Winkel JG: Immunoglobulin A-mediated protection against Bordetella pertussis infection. Infect Immun 2001, 69:4846-4850.

22. van Spriel $A B$, van den Herik-Oudijk IE, van Sorge NM, Vile HA, van Strijp JA, van de Winkel JG: Effective phagocytosis and killing of Candida albicans via targeting FcgammaRI (CD64) or FcalphaRI (CD89) on neutrophils. J Infect Dis 1999, 179:661-669.

23. Morton HC, van Zandbergen G, van Kooten C, Howard CJ, van de Winkel JG, Brandzaeg P: Immunoglobulin-binding sites of human FcalphaRI (CD89) and bovine Fcgamma2R are located in their membrane-distal extracellular domains. J Exp Med 1999, 189:1715-1722.

24. Joos C, Marrama L, Polson HE, Corre S, Diatta AM, Diouf B, Trape JF, Tall A, Longacre S, Perraut R: Clinical protection from falciparum malaria correlates with neutrophil respiratory bursts induced by merozoites opsonized with human serum antibodies. PLoS One 2010, 5:e9871.

25. Roopenian DC, Akilesh S: FcRn: the neonatal Fc receptor comes of age. Nat Rev Immunol 2007, 7:715-725

26. Morell A, Skvaril F, Noseda G, Barandun S: Metabolic properties of human IgA subclasses. Clin Exp Immunol 1973, 13:521-528.
27. Rifai A, Mannik M: Clearance kinetics and fate of mouse $\lg A$ immunecomplexes prepared with monomeric or dimeric IgA. J Immunol 1983, 130:1826-1832.

28. Jafarshad A, Dziegiel MH, Lundquist R, Nielsen LK, Singh S, Druilhe P: A novel antibody-dependent cellular cytotoxicity mechanism involved in defense against malaria requires costimulation of monocytes FcgammaRII and FcgammaRIII. J Immunol 2007, 178:3099-3106.

29. Patry C, Herbelin A, Lehuen A, Bach JF, Monteiro RC: FC alpha receptors mediate release of tumour necrosis factor-alpha and interleukin- 6 by human monocytes following receptor aggregation. Immunology 1995, 86:1-5.

30. Reljic R, Crawford C, Challacombe S, Ivanyi J: Mouse monoclonal IgA binds to the galectin-3/Mac-2 lectin from mouse macrophage cell lines. Immunol Lett 2004, 3:51-56.

31. Mancardi DA, lannascoli B, Hoos S, England P, Daeron M, Bruhns P: FcgammaRIV is a mouse IgE receptor that resembles macrophage FcepsilonRI in humans and promotes IgE-induced lung inflammation. J Clin Invest 2008, 118:3738-3750.

32. Furuta T, Imajo-Ohmi S, Fukuda H, Kano S, Miyake K, Watanabe N: Mast cell-mediated immune responses through IgE antibody and Toll-like receptor 4 by malarial peroxiredoxin. Eur J Immunol 2008, 38:1341-1350.

33. Burghaus PA, Holder AA: Expression of the 19-kilodalton carboxy-terminal fragment of the Plasmodium falciparum merozoite surface protein-1 in Escherichia coli as a correctly folded protein. Mol Biochem Parasitol 1994, 64:165-169.

\section{doi:10.1186/1472-6750-11-77}

Cite this article as: Shi et al:: The generation and evaluation of recombinant human IgA specific for Plasmodium falciparum merozoite surface protein 1-19 (PfMSP1 19). BMC Biotechnology 2011 11:77.

\section{Submit your next manuscript to BioMed Central and take full advantage of:}

- Convenient online submission

- Thorough peer review

- No space constraints or color figure charges

- Immediate publication on acceptance

- Inclusion in PubMed, CAS, Scopus and Google Scholar

- Research which is freely available for redistribution

Submit your manuscript at www.biomedcentral.com/submit
Biomed Central 